\title{
Use of talc to control problems associated with dissolved and colloidal material in papermaking
}

A. Tijero*, M.C. Monte, A. Blanco and J. Tijero

Chemical Engineering Department. Complutense University of Madrid.

Avda. Complutense, s/n. 28040 Madrid (Spain)

atijero@quim.ucm.es

\begin{abstract}
Increasingly stringent environmental standards and market demands are forcing pulp and paper mills to minimize both their water usage and their effluent discharge. The higher rate of process water reuse in pulp and paper mills leads to an increase in the amount of dissolved and colloidal substances in the process water, being this one of the most important limiting factors to achieve a further closure of the water circuits. This study analyzes the use of different types of talcs as control agent of the detrimental properties originated from dissolved and colloidal material contained in two different white waters from paper mills using recovered and coated paper as raw materials respectively. It also identifies the kind of talcs that can be used to control detrimental properties of the white waters.

The results show that talc addition to pulps reduce significantly the detrimental properties of the waters in terms of total solids, cationic demand, chemical oxygen demand, turbidity and can produce high reductions of deposition problems associated to detrimental substances.
\end{abstract}

Keywords: Talc, detrimental properties, dissolved and colloidal material, modified talc, deposition rotor.

\section{INTRODUCTION}

\section{Detrimental properties origin in papermaking}

A large number of contaminants are accumulated in the process as dissolved and colloidal material (DCM) due to trends in papermaking to achieve a high degree of water systems closure or to use higher ratios of recovered paper (RP) as raw material. This detrimental material dispersed in the aqueous phase may cause severe problems in the papermaking process in which small variations of $\mathrm{pH}$, temperature, conductivity and charge density can disturb the chemical balance in the wet end and cause retention variations, or deposition problems. Detrimental phenomena can be controlled by using chemical additives to adsorb detrimental substances, by using advanced process control methods and/or by reducing the contaminant load of the process water with help of 
internal purification methods. Several studies have shown the DCM can be removed from the suspension by adsorption onto fillers [1-5].

To solve the problems associated with the use of recycled raw materials, a higher number of process chemicals are used during papermaking. These additives become potential contaminants when they are introduced again in the system with the recycled paper or with the reused water. The excess of chemicals, the interaction with contaminants already present in the water and the incompatibility between different additives represent a potential problem that has to be considered when chemicals are selected because they may destabilise the DCM and form deposits known as secondary stickies. These problems are worse when the water system is closed due to the accumulation of contaminants in the process. Furthermore, DCM not only interacts with organic substances but also with inorganic and microbial compounds forming combined deposits that favour foaming, scaling, corrosion, etc. [6, 7]. In this case, it is necessary to know the origin of the deposit to be able to control its effects.

Traditionally, talc has been one of the principal fillers used as DCM control agent . Talc is a mineral composed of hydrated magnesium silicate with the chemical formula $\mathrm{Mg}_{3} \mathrm{Si}_{4} \mathrm{O}_{10}(\mathrm{OH})_{2}$ [3-12]. Although talc is often found with other minerals such as carbonates, it is mostly found associated with chlorite. Chlorite is a hydrated magnesium and aluminium silicate with the chemical formula $\left(\mathrm{Mg}_{6}-\mathrm{X}-\mathrm{y} \mathrm{Fe}_{\mathrm{y}}\right.$ $\left.\mathrm{Al}_{\mathrm{x}}\right) \mathrm{O}_{10}(\mathrm{OH})_{8}$ and it is structurally and chemically very similar to talc. Talc is the clay with the lowest surface energy, while chlorite is one of the highest surface energy clay minerals, being much more hydrophilic and polar than talc $[9,13]$. The ratio between lipophilic to hydrophobic surface areas is a property related to the mineralogical composition of talc. Their values are maximum in talcs with a high content of mineral talc and decrease with the chlorite content. This property also increases with the delaminating during the milling due to the fact that basal surfaces are hydrophobic and the edges are hydrophilic [12].

\section{MATERIALS AND METHODS}

\section{Characteristics of the Studied Talcs}

In the experimentation carried out, five commercial talcs were used. The talcs correspond to two groups of different mineralogical compositions: group A, with high concentration of talc and some dolomite, and group B, with medium concentrations of 
talc and chlorite [12]. The mineralogical composition measured by X Ray Diffraction and the physic properties of both talc groups are summarized in tables 1 and 2 , respectively.

Table 1.- Mineralogical composition of talcs (\%)

\begin{tabular}{|c|c|c|c|c|c|}
\hline & \multicolumn{3}{|c|}{ GROUP A } & \multicolumn{2}{|c|}{ GROUP B } \\
\hline & $\overline{\mathbf{A}}$ & A-T & $\overline{A-K}$ & $\overline{\mathbf{B}}$ & $\overline{B-K}$ \\
\hline Talc (1), $\mathrm{Mg}_{3} \mathrm{Si}_{4} \mathrm{O}_{10}(\mathrm{OH})_{2}$ & 85.4 & 82.4 & 94.3 & 61.7 & 55.7 \\
\hline Talc (2), $\mathrm{Mg}_{3} \mathrm{Si}_{4} \mathrm{O}_{11} \mathrm{nH}_{2} \mathrm{O}$ & 13.2 & 16.0 & - & - & - \\
\hline Dolomite, $\mathrm{CaMg}\left(\mathrm{CO}_{3}\right)_{2}$ & 1.3 & 1.5 & 4.2 & - & - \\
\hline Calcite, $\mathrm{CaCO}_{3}$ & - & - & 0.3 & - & - \\
\hline Quarz, $\mathrm{SiO}_{2}$ & 0.1 & 1.5 & 0,3 & 0.5 & 0.4 \\
\hline Clinochlore, $\mathrm{Mg}_{5} \mathrm{Al}\left(\mathrm{Si}_{3} \mathrm{Al}\right) \mathrm{O}_{10}(\mathrm{OH})_{8}$ & - & - & - & 37.0 & 42.1 \\
\hline Ferrous and calcium oxide, $\mathrm{Ca}_{2} \mathrm{Fe}_{7} \mathrm{O}_{11}$ & - & - & - & 0.9 & 1.8 \\
\hline
\end{tabular}

Table 2.- Physic properties of talcs

\begin{tabular}{cccccc}
\hline & \multicolumn{3}{c}{ GROUP A } & \multicolumn{2}{c}{ GROUP B } \\
\hline Talc & A & A-T & A-K & B & B-K \\
Specific area BET $\left(\mathbf{m}^{\mathbf{2}} / \mathbf{g}\right)$ & 12 & 14 & 12 & 8,5 & 8,5 \\
Density $\left(\mathbf{g} / \mathbf{c m}^{\mathbf{3}}\right)$ & 2.80 & 2.78 & 2.80 & 2.78 & 2.78 \\
Hardness $(\mathbf{M o h s})$ & 1 & 1 & 1 & $1-2$ & $1-2$ \\
Zeta potential $(\mathbf{m V})$ & -69 & -69 & +45 & -55 & +30 \\
$\mathbf{H}_{\mathbf{2}} \mathbf{O}$ adsorbed $(\boldsymbol{\%})$ & 15 at $120^{\circ} \mathrm{C}$ & $<1$ & 1 at $120^{\circ} \mathrm{C}$ & $>0,5$ & $>0,5$ \\
$\mathbf{p H}(\mathbf{d i s p e r s i o n ~} \mathbf{1 0} \%)_{\mathbf{d}_{\mathbf{5 0}}(\boldsymbol{\mu} \mathbf{m})}^{9}$ & 4,2 & 8,5 & 9 & 9,5 & 9,5 \\
\hline
\end{tabular}

\section{Preparation of the talc suspensions}

Talc suspensions were prepared at $5 \mathrm{wt} \%$ in Milli-Q water and stirred overnight at the natural $\mathrm{pH}$.

\section{Raw materials}

Two kinds of raw materials were used to obtain different detrimental substances in white waters:

\section{- Recovered paper}

The recovered paper grade used for this study was an Ordinary Grade (1.05) from the r̃European List of Standard Grades of Recovered Paper and Boardò published jointly by the Confederation of European Paper Industry (CEPI) and the Bureau of International Recycling (BIR). This grade is composed of boards and it is used as raw material for packaging paper, specifically for old corrugated container board (OCC). 


\section{- Coated paper}

The coated paper used was a coated silk paper and was provided by UK Paper. This raw material was selected for its high content in dissolved and colloidal material and its tendency to form white pitch deposits. The composition of the coated paper used in this work is show in Table 3.

Table 3.- Coated paper composition (\%)

\begin{tabular}{cc}
\hline Limestone & 71 \\
\hline English Kaolin & 17.8 \\
\hline $\begin{array}{c}\text { Latex acrylonitrile- } \\
\text { butadiene-styrene }\end{array}$ & 8.9 \\
\hline $\begin{array}{c}\text { Carboxymethyl cellulose } \\
\text { sodium salt }\end{array}$ & 0.4 \\
\hline Optical whitening agent & 0.9 \\
\hline Pigment Violet & Traces \\
\hline Sodium hydroxide & Traces \\
\hline Urea- formaldehyde resin & Traces \\
\hline
\end{tabular}

\section{Water collection and characterization}

The raw materials were soaked for $10 \mathrm{~min}$ in tap water to facilitate their defibration. Disintegration was carried out in a lab disintegrator ISP 692 (Investigación Sistemas Papeleros S.A), according to the standards ISO 5263, TAPPI T205 and SCAN C18. Table 4 shows the disintegration conditions used to reproduce mill conditions $[6,17]$. Alkaline $\mathrm{pH}$ conditions, as used in most of the mills, were reached by adding $1 \% \mathrm{NaOH}$ o.d. fibres. The corresponding talc was added to the disintegrated pulp at 3,5\% of consistency. Talc concentrations added to the pulp were $0.1,0.5$, and $5 \%$ of dry weight. Also a blank experiment, without talc addition, was carried out.

\begin{tabular}{lc} 
Table 4.- Disintegration conditions for the raw materials \\
\hline Consistency (\%) & 3.5 \\
pH & 10 \\
Temperature (iC) & 50 \\
Time (min) & 20 \\
Speed (rpm) & 3000 \\
Water volume (L) & 2 \\
\hline
\end{tabular}

A litre of pulp at 3,5\% of consistency was filtrated directly through dynamic drainage jar (DDJ) with a mesh of $100 \mu \mathrm{m}$ and characterized measuring the next parameters: 
- Total solids

Total solids determination was carried out according to the Method 209A of the Standard Methods for the analysis of water of APHA, AWWA and WPCF, by total evaporation of the water in stove at $103-105^{\circ} \mathrm{C}$.

\section{- Cationic demand}

The cationic demand was measured in the supernatant of the white water, after centrifuging at $3000 \mathrm{rpm}$ for $10 \mathrm{~min}$, by colloidal titration with an anionic polyelectrolyte, polyethylenimine (PEI $0,001 \mathrm{~N})$. The titration of the white water was carried out by an automatic titrator CRISON connected to a particle charge detector, Mütek PCD 03.

\section{- Chemical Oxygen Demand (COD)}

The COD method used in this research was by closed reflux and the dichromate excess was determined by procedure $508 \mathrm{~B}$ (volumetric) and by procedure 508C (colorimetric) from Standard Methods: APHA, WWA and WPC [18].

\section{- Turbidity}

The turbidity was measured in the supernatant of the white waters centrifuged at $3000 \mathrm{rpm}$ for 10 minutes by VARIAN Cary 3000 spectrophotometer. The turbidity results were expressed in NTU.

The rest pulp at 3,5\% of consistency was diluted to $0,5 \%$ consistency and it was homogenised by a gentle agitation. Finally, the white water was obtained by filtering the diluted pulp through a DDJ, it was analysed by the deposition rotor.

\section{Deposition experiments}

The depositions experiments were carried out with the deposition tester developed by the Complutense University (UCM) Research Group and described in more detail in previous researches $[6,17,19,20,21]$. The experiments were carried out at $50{ }^{\circ} \mathrm{C}$ for $1 \mathrm{~h}$ and the rotations speed of the rotor was $250 \mathrm{rpm}$. The beaker was filled with $1.8 \mathrm{~L}$ of white waters obtained from the raw materials. 
The deposits collected on stainless steel foils were analysed by an image analysis system ñStickies Measurement Systemò, developed by the British Research Centre PIRA International and the UCM. Results are given as: covered area of deposits expressed as $\mathrm{mm}^{2}, \mathrm{~mm}^{2}$ of deposits per $\mathrm{m}^{2}$ of surface ( $\mathrm{ppm}$ ) and percentage of covered area of deposits $(\%)$. In this paper, the sum of the internal and external deposits, expressed in $\mathrm{mm}^{2}$, (total deposits) are shown. Therefore, the reduction of the depositability is obtained by the equation 1 .

$$
\text { Re duction }(\%)=\frac{\text { Total deposits without talc }- \text { Total deposits with talc }}{\text { Total deposits without talc }} \times 100
$$

The figure 1 shows the schematic representation of the experimental procedure.

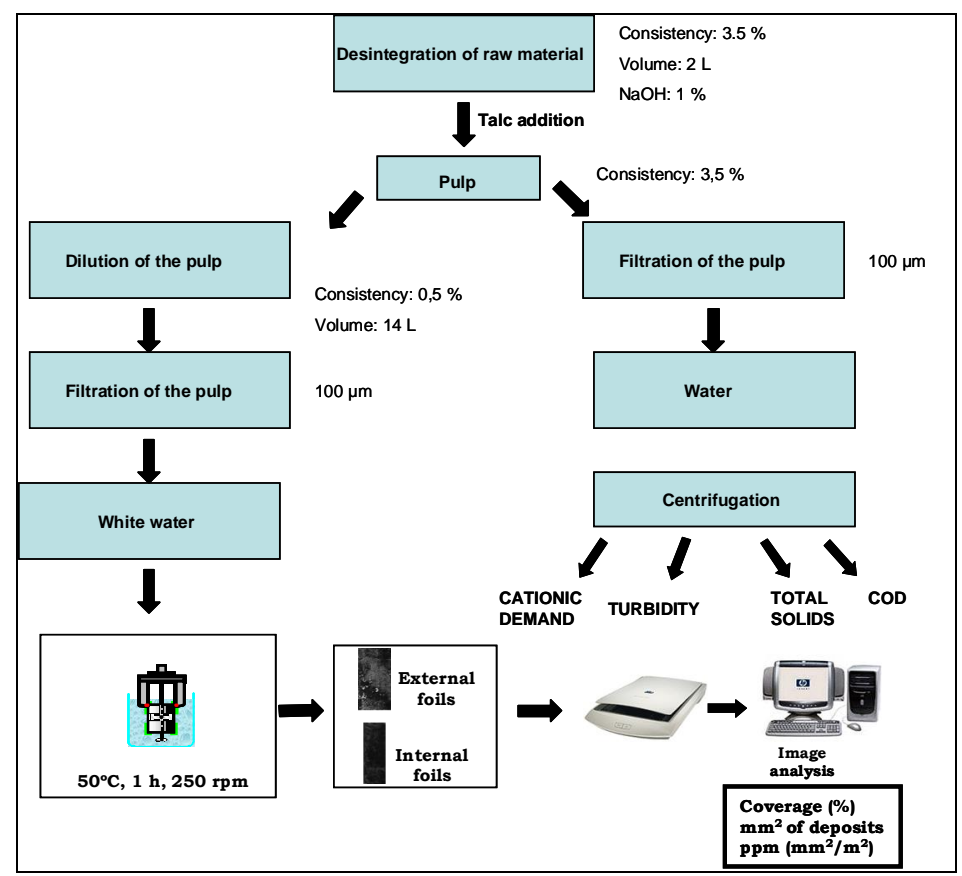

Figure 1 Experimental procedure

\section{RESULTS AND DISCUSSIONS}




\section{Water characterization}

Figures 2 and 3 show the results of the total solids and total solids reduction of the waters from recovered and coated papers for all the talcs studied, respectively.
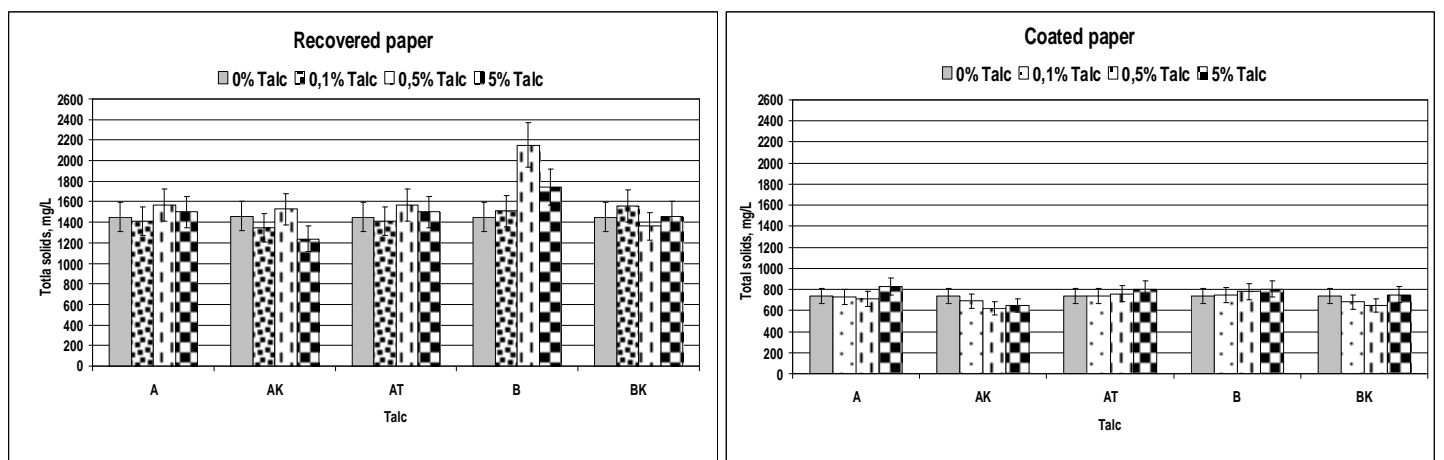

Figure 2. Total solids of the waters using the five talcs studied

The results obtained of the totals solids of the waters from coated were around the half than those obtained with the white waters from recovered paper. The results obtained in both set of trials showed a better performance of cationic talcs in the control of total solids in comparison to the other talcs studied. The best cationic talc was the AK in both sets of experiments at $0,5 \%$ and $5 \%$ of talc concentration, for coated and recovered paper, respectively. The BK talc showed the second best performance of the five talcs studied at $0.5 \%$ of talc concentration with the two types of raw materials considered.
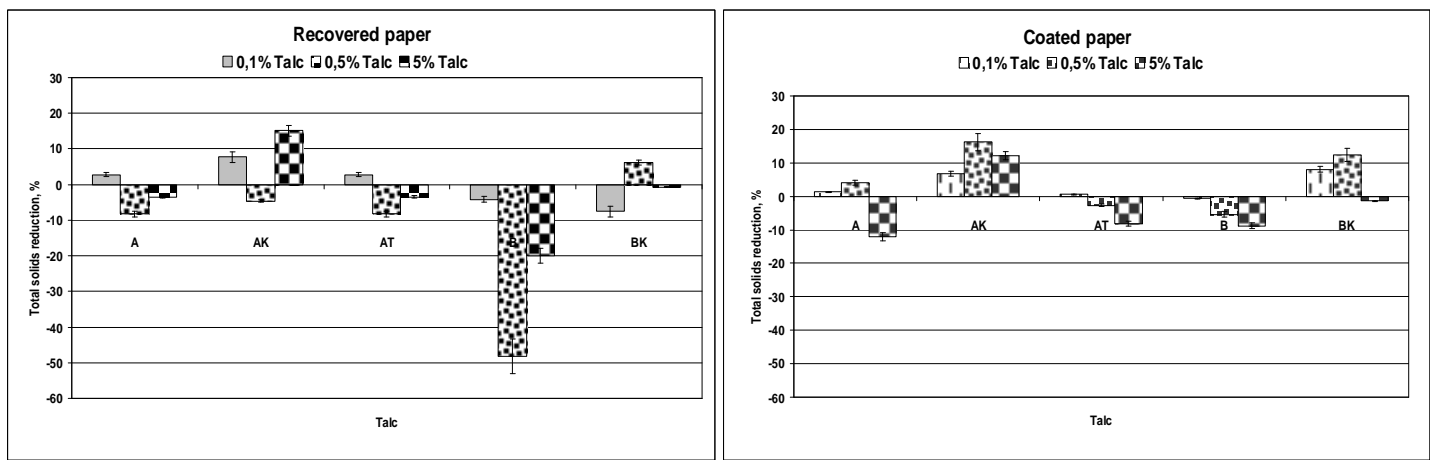

Figure 3. Total solids reduction of the waters using the five talcs studied

The maximum total solids removal was achieved with talc $\mathrm{AK}$ at a talc concentration of 5 and $0,5 \%$ with a reduction $15 \%$ achieved in both raw materials. The predominant mechanism of total solids reduction is considered to be the electrostatic attraction. Talcs act on the dissolved and colloidal material by means of an adsorption process promoted 
by the charges of their surface. Talc AK combines the anionic trash adsorption capacity of the cationic talcs with the surface adsorption capacity of the talc A group. The surface adsorption capacity of talcs is also related to the amount the pure talc in its composition. Talcs AK with a higher talc amount in its composition than talc BK showed a better performance. From the rest of the non-cationic talcs studied only talc A showed a total solids reduction capacity although significantly lower than the obtained with cationic talcs. The failure to remove solids of non-cationic talcs seems to be due to an over-dosage effect caused when certain concentrations of talc were surpassed. This effect can be explained assuming that there was an additional contribution of fine particles coming from the talc added in excess, for which an increase of the total solids was produced.

Figures 4 and 5 show the results of the cationic demand and cationic demand reduction of waters from recovered and coated paper for all the talcs studied, respectively.
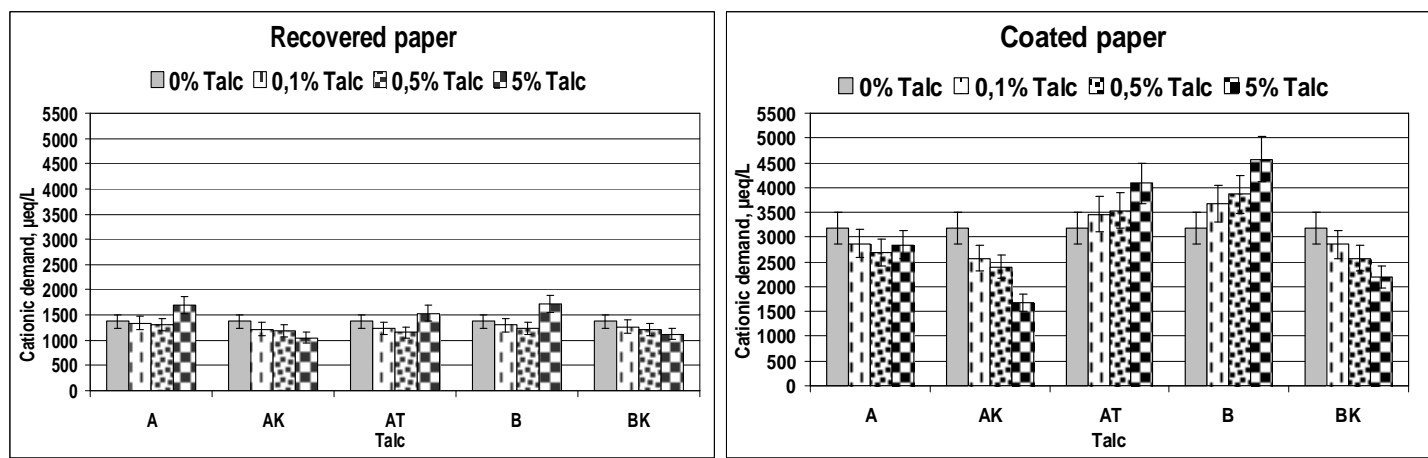

Figure 4. Cationic demand of the waters using the five talcs studied

The results on cationic demand obtained in the waters from coated and recovered paper were quite different. The waters associated to recovered paper had cationic demands around $1400 \mu \mathrm{q} / \mathrm{L}$ and the waters from coated paper trials around of $3500 \mu \mathrm{q} / \mathrm{L}$. The addition of non anionic talc decreased the cationic demand of the recovered paper waters when talcs were added at low and medium concentrations up to $5 \%$ of talc concentration. At high talc concentrations, 5\%, non cationic talcs caused an increase of the cationic demand in the waters, which reached values higher than those obtained in the blank trials in the case of recovered paper. The cationic demand of the waters from recovered paper and coated paper increased when talcs AT and B were added owing to the anionic character of these kinds of talcs. Talc A, with high talc content, produced a 
decrease in the cationic demand when it was added, except when talcs were added to the pulps from coated paper up to reaching the higher concentrations mentioned. In those cases, the addition of talc led to an increase in cationic demand. The addition of cationic talcs, talc $\mathrm{AK}$ and $\mathrm{BK}$, showed a decrease of the cationic demand in the waters at the talc concentration studied and for both kinds of raw materials used. The performance of cationic talcs was seen to improve with talc addition. The best performance was obtained using cationic talc at a concentration of 5\% for both types of white waters. The best performance of the non cationic talcs was observed when employing talc AT and talc $\mathrm{A}$ at $0,5 \%$ talc concentration in the recovered paper trials and talc $\mathrm{A}$ at $0,5 \%$ talc concentration in the recovered paper trials.


Figure 5. Cationic demand reduction of the waters using the five talcs studied

The first additions of cationic talcs originate comparatively greater reductions with a minor amount of talc. Therefore, the reduction is not lineal with the concentration of talc. The addition of anionic talcs increases the cationic demand, when they are incorporated at high enough concentrations in the recovered paper pulp. In coated paper, the anionic talcs AT and B induced, immediately after talc addition, and increase in the cationic demand with respect to the value of this property obtained in the blank trials. The best results were obtained with cationic talc A-K. The better performance of talc $\mathrm{AK}$ with respect to talc $\mathrm{BK}$ and the performance of talc $\mathrm{AT}$ and $\mathrm{A}$ in the recovered and coated paper trials indicate that the principal factor implied in the cationic demand reduction is the cationic charge of the talc added, being the second most important factor the amount of pure talc in the mineral talc employed. The talc lypophilic retention capacity to adsorb the anionic trash leads to a decrease in the cationic demand.

Figures 6 and 7 show the results of the COD and COD reduction of the water from recovered and coated paper for all the talcs studied, respectively. 




Figure 6. COD of the waters using the five talcs studied

The organic material present in the samples analysed corresponds to the organic material not retained in the drainage, nor separated by centrifugation in a posterior step. It is, therefore, organic material dissolved or in true colloidal dispersion, being therefore non separable by centrifugation. The COD data are referred to the colloidal and no colloidal material. The COD results of the waters from both kinds of raw material were quite different. The COD values of the white waters prepared from coated paper were two times higher than those measured in the white waters from recovered paper. The results showed a decrease in the amount of COD obtained with the addition of talcs. The lowest COD value was obtained wit talc $\mathrm{AK}$ at $0,1 \%$ and $5 \%$ concentration in waters from recovered and coated paper respectively. Talc AK showed the best performance in both set of trials.
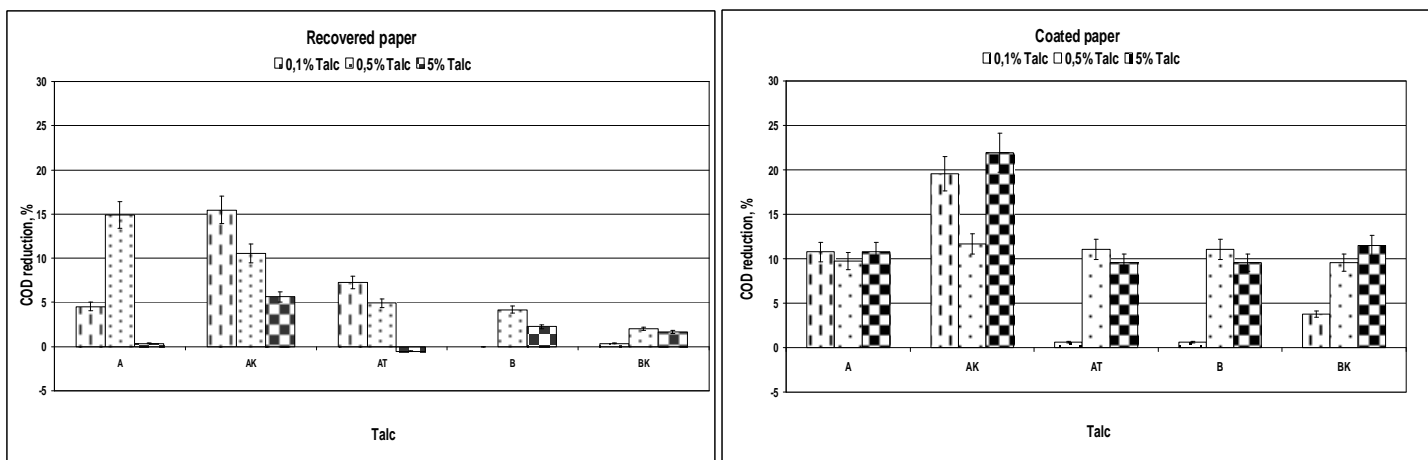

Figure 7. COD of the waters using with the five talcs studied 
The greatest COD reduction, namely $15 \%$, was obtained with talc $\mathrm{AK}$ at $0,1 \%$ of talc contents in recovered paper. The greatest COD reduction performance in coated paper, $21 \%$, was also obtained with talc AK with at $5 \%$ of talc concentration. However, similar COD reductions for both raw materials were obtained at $0,5 \%$ talc concentration. The worst results were obtained with talc AT at high concentrations with an increase of the COD. Cationized talcs with high talc content showed the best performance in terms of COD reduction for both experimental sets. From the results it can be inferred that the good COD removal achieved may be due to the lypophilic retention capacity of talc. The inner surfaces created in talcs subjected to heat treatment, like talc AT, seems to affect negatively the organic compounds adsorption in talc, possibly due to the difficulty of DCM particles to access this news surfaces. The mechanism though which talc A and AK interact with the DCM seems to be governed be an adsorption process. The adsorption capacity of colloidal material over talc AT is comparable to that over talc A.

Figures 8 and 9 show the results of turbidity and turbidity reduction in the water from recovered and coated paper for all the talcs studied, respectively.


Figure 8. Turbidity of the waters using the five talcs studied

The turbidity values measured in the waters from each kind of raw materials were quite different. Turbidity from the waters from coated paper was twelve times higher than the measured in the white waters from recovered paper. The lowest turbidity was observed with the treatment with talc B and the group of A talcs. In particular talcs AT and A at medium talc concentration in the recover paper trials and cationic talcs AK and BK at highest talc concentration studied in the coated paper trials. The turbidity is a property 
directly related to the presence of solids in suspension in the paper both of organic and inorganic nature: carbonate calcium, clays or the same talc, fibres and fines, particles of extractive in emulsion or in suspension, adherent material in dispersion and particles of latex. The correlation between concentration of solids in suspension and turbidity is difficult to establish, given that the form, size and refraction index of the particles in suspension have an important influence in the values measured. Thus, it is possible to produce different dispersions at equal concentration of matter, but with different degree of aggregation or of dispersion of their particles.
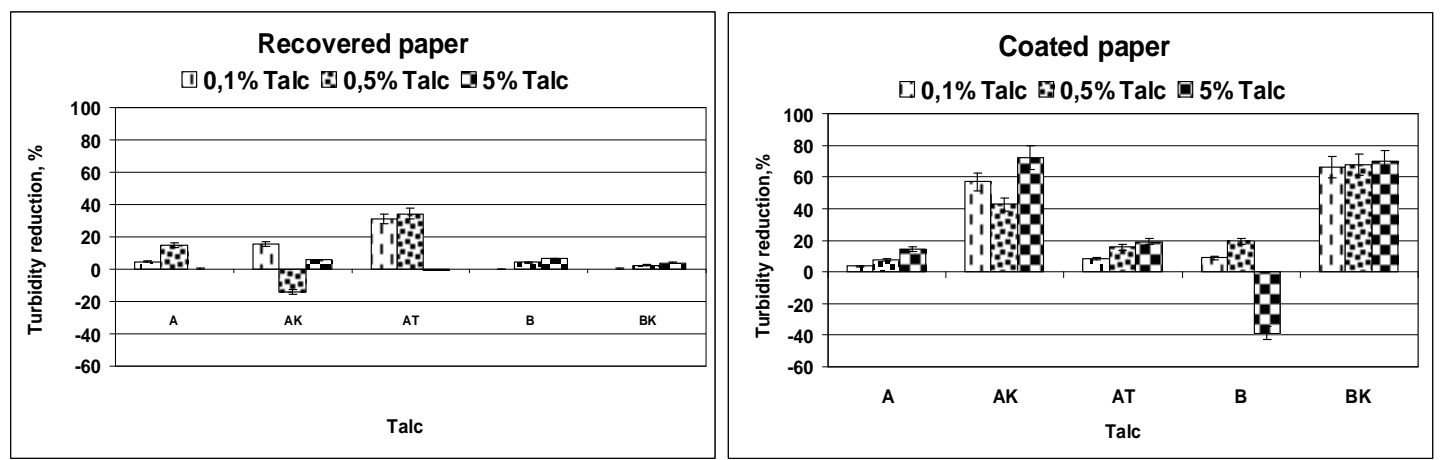

Figure 9. Turbidity reduction of the white waters using the five talcs studied

The greatest reduction in turbidity achieved in the recovered paper trials, namely $34 \%$, was obtained with talc AT at $0.5 \%$ talc concentration. The second best performance was observed using cationic talc $\mathrm{AK}$, with a $15 \%$ turbidity reduction at $0,1 \%$ of talc concentration. The greatest reduction in the coated paper trials was obtained with cationics talc $\mathrm{AK}$ and $\mathrm{BK}$ at low and medium talcs concentrations, i.e. $72 \%$ of turbidity reduction at $0,5 \%$ of talc $\mathrm{AK}$ concentration and $69 \%$ at $0,5 \%$ of talc $\mathrm{BK}$ concentration respectively. At high talc concentrations, the reduction of turbidity is worse, possibly due to the grinding and delamination of talcs that contribute to the turbidity at higher concentrations.

It is considered that the predominant mechanism governing the reduction of the DCM throught the use of talcs in the white waters is an adsorption process. For cationic talcs the mechanism is the sum of the electrostatic and liphophilic adsorption Talc A showed to be the most efficient on turbidity removal among the non cationic talcs due to its capacity as lipophilic adsorbent. Since talcs have a relatively high density compared to other particulate material, $2.8 \mathrm{~g} / \mathrm{cm}^{3}$, the union of talc particles in dispersion with other 
constituents, increases the sedimentation of aggregates by gravity or gravity induced centrifugal acceleration, both by increasing their size their density.

\section{Depositability experiments}

Figure 10 and 11 show the results of the depositability and depositability reduction of the white water from recovered and coated paper for all talcs studied, respectively.


Figure 10. Depositability of the white waters using the five talcs studied

The depositabilty obtained in the white water from recovered paper showed to be significantly smaller than the obtained in the white water from coated paper. In both set of trials the addition of talc showed a decrease in the depositabilty in comparison to to the blank except with the talc AT at the highest of the talc concentration studied,namely $5 \%$. The increase of the concentration added does not lead to the decrease of the depositability, instead, in some cases the addition of talc increase the depositability. Talc A showed the best performances, lowest deposition capacity, with all talc concentrations studied in both kinds of raw materials. The lowest deposition capacity was observed at $0,1 \%$ and $0,5 \%$ concentration of talc $\mathrm{A}$ in the recovered paper and coated paper trials, respectively. The worst performance was observed with talcs BK and $\mathrm{AT}$ at $5 \%$ of talc concentration in recovered and coated paper trials, respectively.
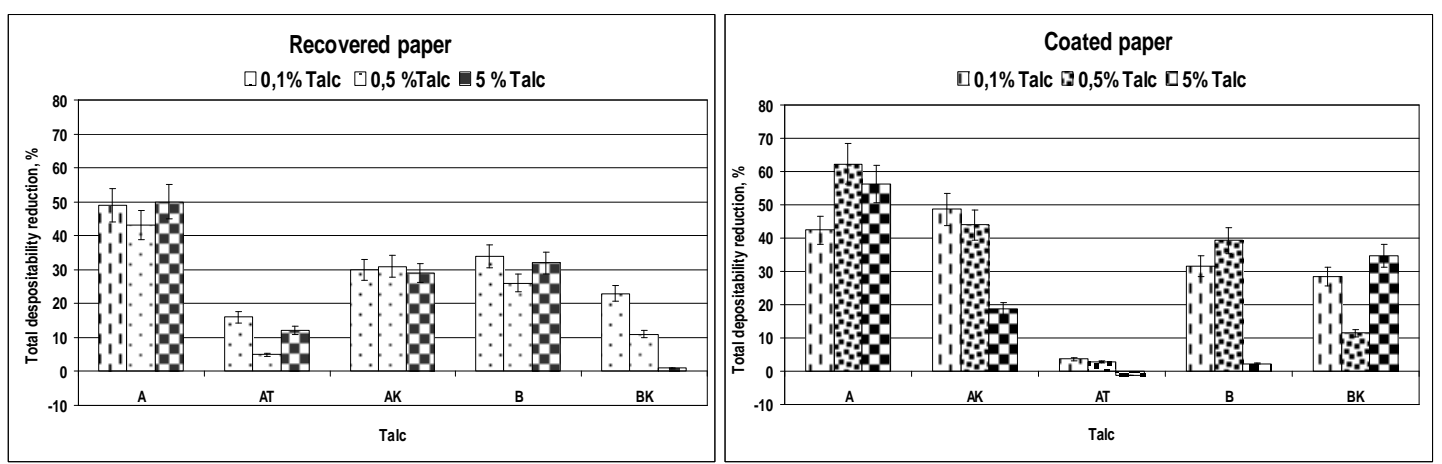

Figure 11. Depositability reduction of the white waters using the five talcs studied 
Talc A, with a high talc concentration and without modifications, produced the best deposition reduction, around 50\% for all talc concentrations in the DCM from recovered paper, and around $62 \%$ for $0,5 \%$ of talc concentration in the DCM from coated paper. The specific surface of the talcs increases with the content in mineral talc and the capacity of talcs to retain DCM are related to their basal surface. Talcs A and AK have the highest BET surface of all talcs studied.

Talc AT, with a high talc concentration and modified through heat treatment, showed the worst performance in the trials with DCM from coated paper with a negative deposition reduction of around $2 \%$ at $5 \%$ talc concentration, being the second worst performance the one achieved with talc BK in the trials with DCM from recovered paper, leading to a deposition reduction of around $5 \%$ at $0,5 \%$ talc concentration.

A talc modified through heat treatment keeps its mineral composition and increases its strong affinity for many types of organic molecules being strongly hydrophobic. The treatment has a low influence on the overall distribution of micropores and mesopores in the particles of talc. However, the inner surfaces created with these treatments could not be accessible to the DCM particles explaining the low performance in controlling DCM from both kinds of raw materials. These results imply that the talc content is the principal characteristic necessary to control the amount of deposits.

Talc AK showed, with a $48 \%$ of depositability reduction at $0,1 \%$ talc concentration, a better performance in the coated paper trials than in the recover paper trials, $48 \%$. The reduction of deposits reached using the talc AK was only $31 \%$, very similar results to the results obtained with talc BK in the recovered paper trials. The lower reduction of the depositability capacity of cationised talc AK could be explained assuming that the presence of cationic charges in its surface does not increase the affinity of talc to DCM particles because the cationic groups would form a layer of water molecules attached to the polyelectrolyte though their negative polar charges that would partially occupy along with the adsorbed molecules of polyelectrolyte.

As summary, in the tables 5 and 6, the highest reductions of the different parameters for each type of raw material is shown. 
Table 5.- Highest reduction of the parameters obtained of the white waters from coated paper

\begin{tabular}{cccc}
\hline Parameter & Highest reduction, $\%$ & Talc & Talc concentration, \% \\
\hline Total Solids & $\sim 15$ & AK & 0,5 \\
\hline Cationic Demand & $\sim 50$ & AK & 5 \\
\hline COD & $\sim 21$ & AK & 5 \\
\hline Turbidity & $\sim 10$ & AK & 5 \\
\hline Depositability & $\sim 60$ & A & 0,5
\end{tabular}

Table 6.- Highest reduction of the parameters obtained of the white waters from recovered paper

\begin{tabular}{cccc}
\hline Parameter & Highest reduction, $\%$ & Talc & Talc concentration \\
\hline Total Solids & $\sim 15$ & AK & 5 \\
\hline Cationic Demand & $\sim 25$ & AK & 5 \\
\hline COD & $\sim 15$ & AK & 0,1 \\
\hline Turbidity & $\sim 30$ & AT & 0,5 \\
\hline Depositability & $\sim 50$ & A & 5 \\
\hline
\end{tabular}

\section{Conclusions}

Talc can be employed as an agent to reduce the detrimental properties of the paper mill process water. In addition to the traditional use of talc as adherent material and control agent, talc can be used as control agent of other detrimental properties such as turbidity, COD, cationic demand and total solids. The performance of each talc as detrimental control agent is different.

Cationic charged talcs showed the best total solids control performance. Talc AK showed the best performed to control the total solids in both set the trials at $5 \%$ talc concentration, in recovered paper, and $0,5 \%$, in coated paper with a cationic demand reduction of around $15 \%$ in both raw materials.

Cationic charged talc AK showed the best performance to control the cationic demand among all the talcs studied. The best performance of AK was at 5\% talc concentration, with a cationic demand reduction around $25 \%$, and at $0,5 \%$ with a cationic demand reduction of around $50 \%$, for waters from recovered and coated paper, respectively. 
Cationic charged talc AK showed the best performance of all the talcs studied in the control the COD. The best performance of AK was at $0,1 \%$, with a COD reduction of around $15 \%$, and $5 \%$ of talc concentration, with a COD reduction of around $20 \%$, for white waters from recovered and coated paper respectively.

Thermally treated talc AT at $0,5 \%$ concentration yielded the best results in the removal of turbidity for white waters from recovered paper, with a turbidity reduction of around $30 \%$. Cationic talc AK, at $5 \%$ of talc concentration, showed the best performance to control the turbidity of the white waters from coated paper with a turbidity reduction of 70

The best talcs to control the depositability were the ones non-surface treated with high talc content in their composition, talc A. Talc A showed the best performance at 0,5\%, with a depositability reduction of around $60 \%$, and $5 \%$ talc concentration, with a depositability reduction of around 50\%, from white waters from coated and recovered paper, respectively.

\section{Acknowledgements}

The authors wish to express their appreciation to Luzenac for the supply of the talcs and UK Paper for the supply of the coated paper used and Patrico López Expósito for his assistance.

\section{BIBLIOGRAPHY}

1- WILLFÖRD, S., A. SUNBERG, A. L. SIHVONEN, B. HOLMBOM, గ̃nteractions between fillers and dissolved and colloidal substances from TMPò Pap. Puu Ï Pap. Tim. 82 (6): 398 (2000).

2- NYLUND, J., SUNDBERG, A. AND SUNDBERG, K. (2007). ர̃Dissolved and colloidal substances from a mechanical pulp suspensionð Interactions influencing the sterical stabilityò Colloids Surfaces A: Physicochem. Eng. Aspects. 301 (1-3): 335-340 
3-WALlQViST, A., CLAESSON, P.M.,SWERIN, A, SCHOELKOPF, J.C. and GANE, P.C., ñnteraction Forces Between Talc and Hydrophobic Particles Probed by AFMò Colloids Surface A - Physicochem. Engin. Aspects 277:183-190 (2006).

4-BIZA, P., ñTalc Solutions for Deposition Problems in Pulp and Paper Processes", Proc. Use of Minerals in Papermaking Conf., Pira Intl., 191-200 (1997).

5-GUERÁ, N., SHOELKOPF, J. and GANE, P.A., r̃Comparing Colloidal Pitch Adsorption on Different Talcsò Nordic Pulp Paper Res. J. 20(2):156-163 (2005).

6-MONTE, M., BLANCO, A., NEGRO, C. and TIJERO, J. ñDevelopment of a methodology to predict sticky deposits due to the destabilisation of dissolved and colloidal material in papermakingð application to different systemsò Chemical Engineering Journal 105 (2004) 21 ï 29

7-OLSON, C.O., LETSCHER, M.K., ก̃ncreasing the use of secondary fibre: an overview of deinking chemistry and stickie controlòAppita J., 45 (2) 58ї 61(1992).

8-WALLQVIST, A., CLAESSON, P.M.,SWERIN, A, SCHOELKOPF, J.C. and GANE, P.C., గ̃nteraction Forces Between Talc and Pitch Probed by Atomic Force Microscopyò Langmuir 23:8: 4248-4256 (2007).

9-TAMURA, H., TSUJIMICHI, K., YAMANO, H., SHIOTA, K., KUBO, M., FAHMI, A. and MIYAMOTO A., ñMolecular Dynamics Simulation of the Friction Between Talc (001) Surfacesò Appl. Surf. Sci. 119(3-4):335-340 (1997).

10-BIZA, P., ñA Modern Solution for Pitch and Stickies Controlò Paper Technol. 42(3): 22-24 (2001).

11-COMARD, M.P., CALVET, R., BALARD, H. and DOODS, J.A., Înfluence of the Geological History, Particle Size and Carbonate Content of the Surface Properties of 
Talc as Determined by Inverse Gas Chromatography at Infinite Dilutionò Colloids Surface A - Physicochem. Engin.Asp. 238(1-3):37-42 (2004).

12-TIJERO, A., MONTE, M.C., BLANCO, A., NEGRO, C., TIJERO, J., ז̃Pitch adsorption on natural and modified talcsò J. Pulp and Pap. Sci., 35(3-4):130-136 (2009).

13-DOILLARD, J.-M., SALLES, F., HENRY, M., MALANDRINI, H. and CLAUSS, F., ñSurface Energy of Talc and Chlorite: Comparison Between Electronegativity Calculation and Immersion Resultsò, J. Colloid Interface Sci. 305(2):352-360 (2007). 14-ISO 5263-1: 2004. Pulps-Laboratory wet disintegration. Part 1: Desintegration of chemical pulps.

15-Test Method T205 sp-1998. ñForming handsheets for physical test of pulpò. Tappi Press.

16-SCAN-C 18:65 Disintegration of Chemical Pulp for Testing (Scandinavian Pulp, Paper and Board Testing Committee, Stockholm, Sweden).

17- MONTE, M.C., MACNEIL, D., NEGRO, C., BLANCO, A. Ĩnteraction of dissolved and colloidal material during the mixing of different pulpsò Holzforschung 64: $277-283$ (2010).

18-APHA, AWWA, WPFC, 1995. ñStandard Methods for Examination of Water and WastewateròEd. 19. Washington D.C.

19-BlanCO, A., NEGRO, C., MONTE, M. C., OTERO, D. y TIJERO, J., ñNew system to predict deposits due to DCM destabilization in paper millsò. Pulp \& Paper Canada. 101: 40-43 (2000).

20-TIJERO A., 2006. ז̃CONTROL DE LA MATERIA DISUELTA Y COLOIDAL ADHERENTE EN LA FABRICACIÓN DE PASTA Y PAPEL MEDIANTE LA UTILIZACIÓN DE TALCOS MODIFICADOSò PhD THESIS, Universidad Complutense de Madrid 2006. 
21-MONTE, M. C., 2000. ñDepósitos adherentes en el proceso de fabricación de papel recicladoò. PhD THESIS, Universidad Complutense de Madrid 2000. 